\title{
THE EFFECTS OF CARVEDILOL AND Q10 ON ISOPRENALINE- INDUCED CARDIOTOXICITY: ELECTROCARDIOGRAPHIC, BIOCHEMICAL AND HISTOPATHOLOGICAL EVALUATION IN RATS. BY
}

Nora Elshourbagy ${ }^{\mathrm{a}}$, Wesam M. El-Bakly ${ }^{\mathrm{b}}$, Samar Azab $^{\mathrm{c}}$, Azza Awad $^{\mathrm{d}}$, Ragia Taha ${ }^{\mathrm{d}}$, Ebtehal El-Demerdash ${ }^{\mathrm{c}}$

FROM

${ }^{\text {a }}$ Marketing manager, October Pharma.

${ }^{\mathrm{b}}$ Department of Pharmacology, Faculty of Medicine, Ain Shams University, Cairo, Egypt.

${ }^{c}$ Department of Pharmacology \& Toxicology, Faculty of Pharmacy, Ain Shams University, Cairo, Egypt

${ }^{\mathrm{d}}$ Department Of Pharmacology \& Toxicology, Faculty of Pharmacy, Al Azhar University, Cairo, Egypt

\begin{abstract}
Objective: To assess the therapeutic effect of combining of Carvedilol and Q10 on electrocardiographic, biochemical and histopathological changes in isoprenaline induced myocardial infarction. Methods: Myocardial infarction was induced in rats by subcutaneous (s.c) injection of isoprenaline $(85 \mathrm{mg} / \mathrm{kg}$ ) for two consecutive days at an interval of $24 \mathrm{~h}$. Rats were treated orally (p.o) with Carvedilol at dose $(5 \mathrm{mg} / \mathrm{kg} / \mathrm{day})$ and Q10 at dose $(10 \mathrm{mg} / \mathrm{kg} /$ day $)$ for a period of 14 days. At the end of experiment electrocardiographic, biochemical and histopathological changes were monitored from control and experimental groups. Results: ISP intoxicated rats showed a significant tachycardia, elevation ST and prolongation of QTc (i.e. ST, QTc \& HR) due to conduction abnormalities, increased serum creatine kinase isoenzyme-MB (CK-MB) Treatment with Carv+Q10 significantly improved the ISP induced alteration in ECG, biochemical and histopathological changes. Conclusions: The present result shows that treatment with Carv+Q10 significantly attenuates myocardial infarction in ISPintoxicated rats.
\end{abstract}

\section{Introduction}

Cardiovascular disease (CVD), predominantly myocardial infarction, remains the principal cause of death in both developed and developing countries. It will be the most important cause of mortality worldwide by 2020(Rajadurai and Prince 2007). Myocardial infarction (MI) occurs when the blood supply to a part of the heart is interrupted, causing death of heart tissue (Upaganlawar, Patel et al. 2012). It is an acute condition of necrosis of the myocardium that occurs as a result of imbalance between coronary blood supply and myocardial demand (Upaganlawar, Patel et al. 2012). Inflammation is a key process involved in mediating myocardial tissue damage after an ischemic event. Neutrophils infiltrate the infarcted area where they can promote myocardial cell damage through the release of proteolytic enzymes and the production of reactive oxygen species (ROS). Inflammation may also increase the risk of recurrent ischemic events by destabilizing atherosclerotic plaques and making them prone to rupture (Jordan, Zhao et al. 1999). The development of myocardial ischemia and infarction is a dynamic process with the widespread occurrence of coronary atherosclerosis and involvement of oxidative stress in the humans. Among several 
pharmacological interventions to protect heart against oxidative stress, the use of antioxidants is most promising (Ojha, Bhatia et al. 2011).

Isoprenaline (ISP) [1-(3, 4-dihydroxyphenyl)-2-isopropylaminoethanol hydrochloride] is a synthetic $\beta$-adrenergic agonist and its subcutaneous injection induces irreversible cellular damage and ultimately myocardial infarction in rats. The acute hemodynamic and electrocardiographic changes in isoprenaline induced myocardial infarction resemble closely to those occurring in patients with myocardial infarction(Yousefi, Soraya $\boldsymbol{e t}$ al. 2013). Therefore, the rat model of isoprenaline induced myocardial infarction offers a reliable non-invasive technique for studying the effects of various potentially cardioprotective agents (Fathiazad, Matlobi et al. 2012).

It produces myocardial necrosis which caused cardiac dysfunction, increased lipid peroxidation along with an increase in the level of myocardial lipids, altered activities of the cardiac enzymes and antioxidants (Karthikeyan, Bai et al. 2007).

Carvedilol is a non-selective $\alpha 1$ - and $\beta$-receptor blocker initially used in the treatment of hypertension. In addition to its antihypertensive property, carvedilol has been shown to significantly reduce morbidity and mortality in heart failure and postAMI patients (Liu, Zhang et al. 2013).

Therefore the present study was designed to study the effect of Carvedilol and Q10 treatment on the myocardial infarction induced by supramaximal doses of isoprenaline . And study its therapeutic efficacy by studying the biochemical marker, electrocardiographic and histopathological changes.

\section{Materials and methods}

\subsection{Drugs and chemicals}

1. Carvedilol (Multiapex pharma, Cairo, Egypt). It was obtained as a gift. Carveilol was used as a drug to treat myocardial necrosis in rats. It was dissolved by the initial addition of dimethyl sulphoxide (DMSO), followed by the addition of normal saline (the final concentration of DMSO was less than $0.5 \%$ ).

2. Co-enzyme Q10 (Mepaco pharma, Cairo, Egypt). Co-enzyme Q10 was used as a drug to treat myocardial infarction in rats. It was dissolved in distilled water oral administration.

3. Isoprenaline (Sigma-Aldrich Co., St Louis, MO, USA).

Isoprenaline is (RS)-4-[1-hydroxy-2 (isopropylamino)ethyl]benzene-1,2-diol, $\mathrm{C} 11 \mathrm{H} 17 \mathrm{NO} 3$, It is white crystalline powder .It was dissolved in saline at concentration of $85 \mathrm{mg} / \mathrm{kg}$ to be injected s.c. for 2 consecutive days to induce myocardial infarction.

\subsection{Experimental animals}

Male Sprague-Dawley rats $(200-220$ g) obtained from Nile Co. for Pharmaceutical and Chemical industries (Cairo, Egypt) were used in the present study. Rats were housed in faculty of Pharmacy, Ain-Shams University, in an air-conditioned atmosphere, at a temperature of $25{ }^{\circ} \mathrm{C}$ with alternatively 12 hour light and dark cycles. Animals were acclimated for 2 weeks before experimentation. They were kept on standard pellet diet and water ad libitum.

The study was carried out according to the guidelines of the Ethics Committee, Faculty of Pharmacy, Ain-Shams University. 


\subsection{Induction of myocardial infarction}

Myocardial infarction was induced in rats by subcutaneous injection of 85 $\mathrm{mg} / \mathrm{kg}$ isoprenaline hydrochloride dissolved in saline once daily for two successive days. The selected route and dose were chosen from published literatures (Priscilla and Prince 2009).

\subsection{Experimental design.}

After acclimatization, the animals were randomly divided into the following groups consisting of 8 rats each:

Group 1 (control): rats was injected with normal saline $(1 \mathrm{ml} / \mathrm{kg})$ subcutaneous (S.C.) on the $1^{\text {st }}$ and $2^{\text {nd }}$ day and then received DMSO /distilled water (vehicle for Carvedilol/ Q10 ) orally for 14 days.

Group $2 \operatorname{Carv}(5 \mathrm{mg} / \mathrm{kg})+\mathrm{Q} 10(10 \mathrm{mg} / \mathrm{kg})$ : rats was injected with Normal saline $\left(1 \mathrm{ml} / \mathrm{kg}\right.$ ) subcutaneous (S.C.) on the $1^{\text {st }}$ and $2^{\text {nd }}$ day at an interval of $24 \mathrm{~h}$ then received Carv ( $5 \mathrm{mg} / \mathrm{kg})+\mathrm{Q} 10(10 / \mathrm{kg})$ in DMSO/distilled water orally for 14 days(CHANDER HASS YADAV and KHANAM 2014).

Group 3 (ISP): rats was injected with ISP $(85 \mathrm{mg} / \mathrm{kg}$, S.C.) in normal saline on the $1^{\text {st }}$ and $2^{\text {nd }}$ day at an interval of $24 \mathrm{~h}$ then received DMSO/distilled water orally for 14 days(Dusek, Rona et al. 1971).

Group 4 ISP+ Carv $(5 \mathrm{mg} / \mathrm{kg})+$ Q10 $(10 \mathrm{mg} / \mathrm{kg})$ : rats was injected with ISP (85 $\mathrm{mg} / \mathrm{kg}$, S.C.) in normal saline on the $1^{\text {st }}$ and $2^{\text {nd }}$ day at an interval of $24 \mathrm{~h}$ then received Carv $(5 \mathrm{mg} / \mathrm{kg})+\mathrm{Q} 10(10 \mathrm{mg} / \mathrm{kg})$ in DMSO/distilled water for orally 14 days.

Twenty-four hours after the last treatment, animals were anesthetized with urethane intraperitoneal at dose $(1.5 \mathrm{~g} / \mathrm{kg})$ (Field, White et al. 1993) for ECG monitoring. Thereafter, blood samples were collected from the retro-orbital plexus. Serum was separated by centrifugation at $4000 \mathrm{rpm}$ for $4 \mathrm{~min}$ and stored at $-20^{\circ} \mathrm{C}$ until analysis for the estimation of CK-MB activity. Rats were then sacrificed by decapitation and the hearts were rapidly isolated, and preserved in $10 \%$ formalin for histological examination.

\subsection{Measurements of ECG changes}

Electrocardiograph was recorded at the beginning of the experiment to ensure the normal ECG pattern of the rats according to method of (Mladěnka, Hrdina et al. 2009) At the end of the experiment, ECG was recorded in urethane anesthetized rats 48 $\mathrm{h}$ after ISP injection using Bioscience ECG recorder (Bioscience, Washington, USA). Anesthetized rats were placed in the supine position on a board and needle electrodes were inserted beneath the skin for the limb lead at position II (right forelimb to left hind limb). Every recording lasted for at least $5 \mathrm{~min}$. ECG recording speed was $50 \mathrm{~mm} / \mathrm{s}$ and the voltage was $1 \mathrm{mV} / \mathrm{cm}$. Noise was minimized by a digital filter. Analysis of ECG waves was done to calculate heart rate (beats/min), ST segment (mV) and QTc interval (ms). QTc interval was calculated from Bazett's equation. For each parameter, measurements were done at three non-consecutive, randomly chosen points in every 5 min recording. The results are reported as mean of the three randomly selected segments. 


\subsection{Biochemical assays}

The collected serum was used for the estimation of cardiac marker enzymecreatinine kinase-MB (CK-MB), standard enzymatic kitsaccording to method of Gerhardt \&Waldenström (Gerhardt and Waldenström 1979).

\subsection{Histopathology}

After sacrifice, the heart was rapidly dissected out and washed immediately with saline and fixed in $10 \%$ buffered formalin. The fixed tissues were embedded in paraffin and serial sections ( $5 \mu \mathrm{m}$ thick) were cut. Each section was stained with hematoxylin and eosin (H\&E) according to Banchroft\&Gamble (Ashoush, El-Batawy et al. 2013) . The sections were examined under the light microscope (Olympus BX10, Tokyo, Japan) for histopathological changes and photomicrographs (Olympus DP12 camera, Japan) were taken.

\subsection{Statistical analysis}

All the values are expressed as mean \pm S.D. Statistical significance between more than two groups was tested using one-way ANOVA followed by Tukey-Kramer as a post-hoc test as appropriate using computer based fitting program (Prism, Graphpad). The 0.05 level of probability $(P \leq 0.05)$ was used as the criterion for significance.

\section{$\underline{\text { Results }}$}

\subsection{Effect of Carvedilol and Q10 on ECG changes in isoprenaline-induced myocardial infarction in rats}

Electrocardiograph tracing showed normal cardiac activity in the control and Carv+Q10 treated rats. Rats in ISP-intoxicated group showed several ECG changes including tachycardia, ST-segment elevation and prolongation of QTc intervals as compared to the control group. Such ECG abnormalities were obviously improved in the ISP-intoxicated animals treated with the Carv+Q10 as evidenced by normalization of heart rate, ST-segment and QTc intervals compared to ISP-intoxicated group (Table $1)$.

Table (1): ECG parameters of rats treated with Carvedilol and Q10 and/or isoprenaline (ISP).

\begin{tabular}{|l|l|l|l|}
\hline Treated groups & $\begin{array}{l}\text { ST segment } \\
(\mathrm{mV})\end{array}$ & $\begin{array}{l}\text { QTc interval } \\
(\mathrm{ms})\end{array}$ & $\begin{array}{l}\text { Heart rate } \\
(\mathrm{beat} / \mathrm{min})\end{array}$ \\
\hline Control & $0.10 \pm 0.005$ & $0.31 \pm 0.015$ & $329.9 \pm 7.90$ \\
\hline Carv+Q10 & $0.10 \pm 0.009$ & $0.31 \pm 0.005$ & $313.8 \pm 10.17$ \\
\hline ISP $(85 \mathrm{mg} / \mathrm{kg})$ & $0.25 \pm 0.037^{\mathrm{a}}$ & $0.50 \pm 0.045^{\mathrm{a}}$ & $453.3 \pm 27.33^{\mathrm{a}}$ \\
\hline $\begin{array}{l}\text { ISP }(85 \mathrm{mg} / \mathrm{kg})+ \\
(\text { Carv/Q10) }\end{array}$ & $0.15 \pm 0.033^{\mathrm{b}}$ & $0.35 \pm 0.035^{\mathrm{b}}$ & $305.0 \pm 36.19^{\mathrm{b}}$ \\
\hline
\end{tabular}

Data are the mean \pm S.D. $(n=8)$.

a:Significantly different from the control

b:Significantly different from ISP-intoxicated group respectively at $\mathrm{P} \leq 0.05$ using ANOVA followed by Tukey-Kramer as a post-hoc test. 
3.2. Effect of Carvedilol and Q10 on biochemical change that associate isoprenaline-induced myocardial infarction in rats

Isoprenaline increased serum CK-MB activity by $110 \%$ as compared to the normal group. Carv+Q10 treatment decreased serum CK-MB activity by $41.8 \%$ as compared to the isoprenaline-intoxicated group (Table 2 and Fig 1).

Table (2): Cardiotoxicity marker of rats treated with Carv+Q10 and/or isoprenaline (ISP).

\begin{tabular}{|l|l|}
\hline Treated groups & CK-MB \\
\hline Control & $148.7 \pm 19.33$ \\
\hline Carv+Q10 & $124.2 .4 \pm 20.31$ \\
\hline ISP $(85 \mathrm{mg} / \mathrm{kg})$ & $311.7 \pm 44.12^{\mathrm{a}}$ \\
\hline $\begin{array}{l}\text { ISP }(85 \mathrm{mg} / \mathrm{kg})+ \\
(\text { Carv+Q10) }\end{array}$ & $181.4 \pm 20.85^{\mathrm{b}}$ \\
\hline
\end{tabular}

CK-MB, Creatine phosphokinase isoenzyme-MB.

Data are the mean \pm S.D. $(n=8)$

a: Significantly different from the control

b: Significantly different from ISP-intoxicated group respectively at $\mathrm{P} \leq \mathbf{0 . 0 5}$ using ANOVA followed by Tukey-Kramer as a post-hoc test.

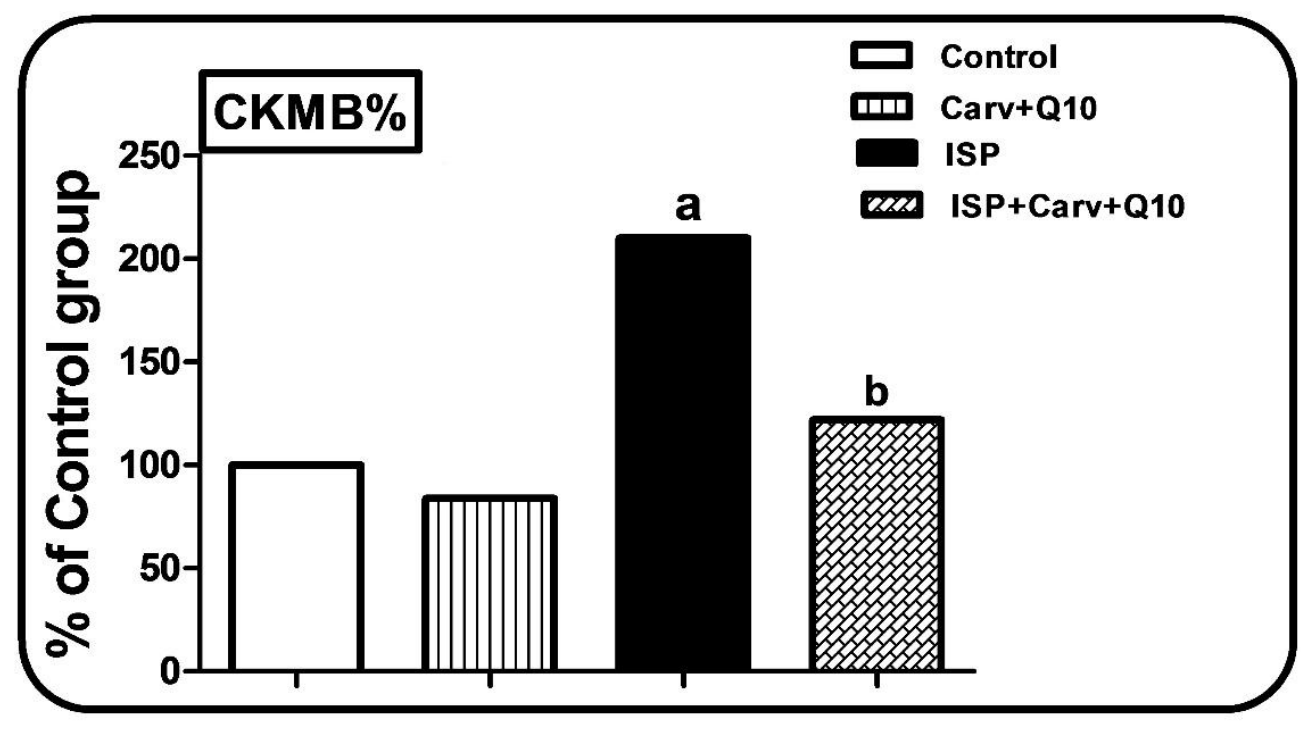

Fig. (1): Effect of Carv+Q10 on $C K-M B$ in ISP-intoxicated group as percentage of control group.

a or b: Significantly different from the control or ISP-intoxicated group respectively at $\mathrm{P} \leq 0.05$ using ANOVA followed by Tukey-Kramer as a post-hoc test. 
3.3. Effect of Carv+Q10 on histopathological changes that associate isoprenalineinduced myocardial infarction in rats

To further characterize the Cardiotoxicity induced by isoprenaline, histopathological examination of heart tissue was done. Hearts from control and Carv+Q10 treated rats showed regular cell distribution and normal myocardium architecture (Fig 2A and 2B). Histological examination of hearts from ISP-intoxicated animals revealed marked myocardial degeneration (D) in the form of myofibrillar loss, cytoplasmic vacuolization (V), inflammatory cell infiltration (I), edema (E) and congestion (Fig. 2C). Interestingly, pretreatment of ISP-intoxicated rats with Carv+Q10 almost preserved the normal myocardium architecture (Fig. 2D).

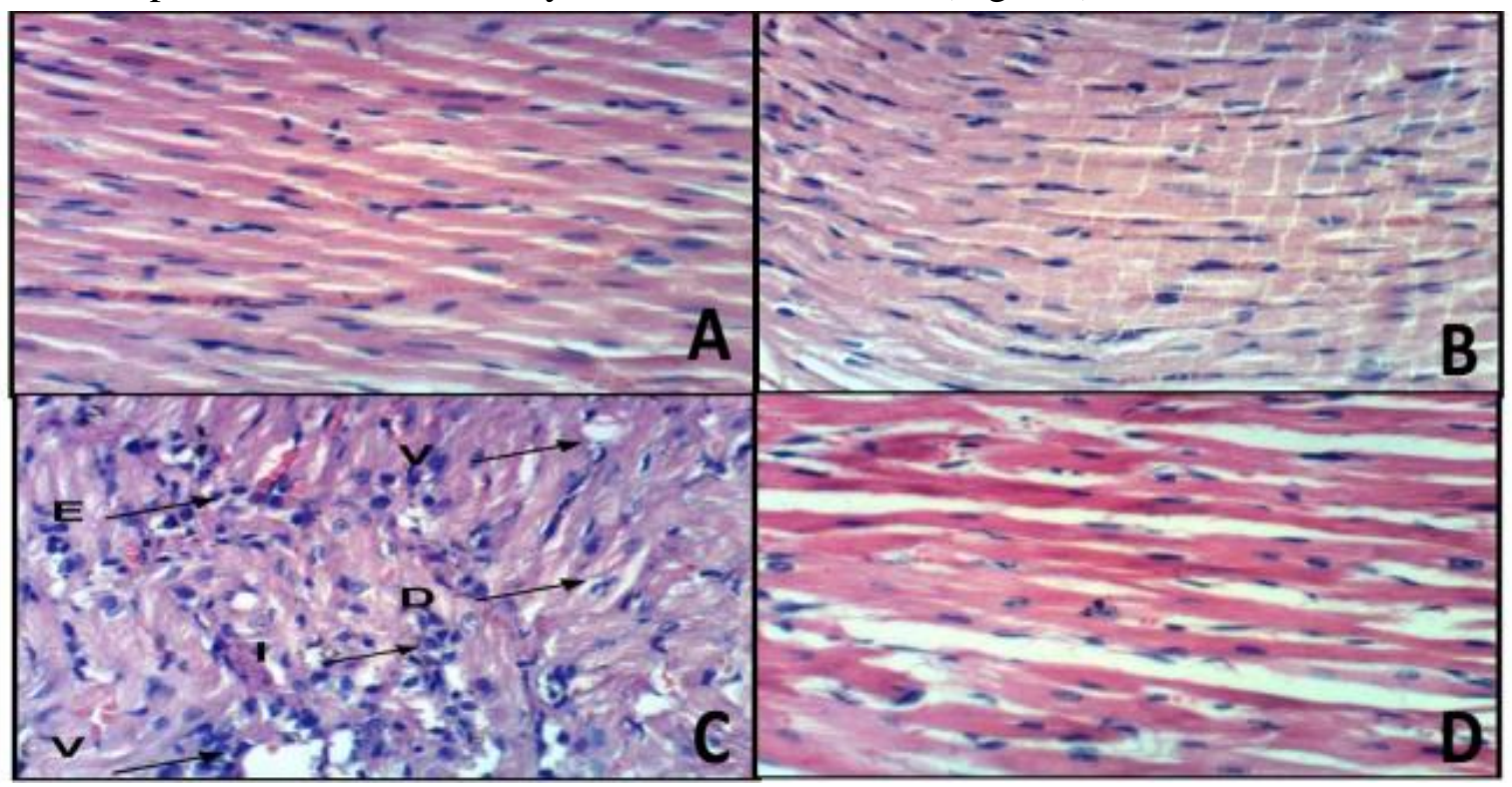

Fig2. Effect of Carv/Q10 treatment on ISP-induced histological alterations of the heart tissue (x200). Photomicrographs of haematoxylin and eosin stained sections of heart depicting (A) control group, (B) Carv/Q10 treated group, (C) ISP treated group $(85 \mathrm{mg} / \mathrm{kg})$ and (D) ISP $(85 \mathrm{mg} / \mathrm{kg})+$ Carv/Q10 treated group. (A) \&(B) show normal histoarchitecture of the rat heart. (C) Show ISP-induced myofibrillar loss, cytoplasmic vacuolization, inflammatory cell infiltration, edema and congestion. (D) Show that Carv/Q10 treatment prevented 


\section{Discussion}

MI induced by injection of ISP is a standardized model to study the beneficial effects of numerous drugs and antioxidants. In the present study, we found that Carvedilol and Q10 treatment exerts a strong improvement in ISP induced MI in rats. The ECG is considered the single most important initial clinical test for diagnosis of myocardial ischemia and infarction. Its correct interpretation is usually the basis for immediate therapeutic interventions and/or subsequent diagnosis tests. In the present study, ISP intoxication shows significant alterations in ECG patterns. The characteristic ECG findings were elevation of ST-segment and QTc interval. These alterations could be due to ISP auto oxidation and generation of free radicals which further produced oxidative stress. Increased oxidative stress causes loss of cell membrane function in injured myocardium (Holland and Brooks 1977). This elevation reflects the potential difference in the boundary between ischemic and nonischemic zones(Patel, Upaganlawar et al. 2010; Li, Xie et al. 2012). Furthermore, STsegment elevation was observed in patient with acute myocardial ischemia and in experimental model of ISP in rats(Peacock, Hollander et al. 2007; Punithavathi and Stanely Mainzen Prince 2011).

Treatment with Carvedilol and Q10 in ISP-intoxicated rats significantly prevented the altered ECG pattern towards normal suggesting the cell membrane stabilizing potential of Carvedilol and Q10 which might be due to their potent antioxidant property which is agreement with previous reports(Cheng, Kamiya et al. 2001).

In the present study ISP-intoxicated rats showed MI which is evident by significant increase in heart rate. These changes in hemodynamic parameter indicated the activation of sympathetic nervous system which is in line with previous reports (Alcaraz, Fernandez et al. 2003)

Treatment with Carvedilol and Q10 significantly attenuated these changes in hemodynamic parameter which are evidenced from improvements in heart rate (Bullinga, Alharethi et al. 2005).

Additionally, ISP-induced myocardial injury was further manifested by the significant elevation in activities of serum CK-MB enzyme; due to leakage from tissue to blood serum as a result of damaged or destroyed cardiomyocytes, as well as, the cells damaged because of insufficient supply of oxygen and oxidative damage of myocardium which render the cell membrane fragile, porous, or ruptured. The increased levels of these enzymes are indicative of severity of cell necrosis and ISP mediated peroxidative myocyte injury. The increase in activities of these enzymes is in agreement with previous studies (Kannan and Quine 2013).

On the other hand, Carvedilol and Q10 treatment significantly ameliorated ISPinduced CK-MB enzymes activities elevations. Furthermore, it almost preserved the normal architecture of the heart which in consonance with previous studies(Brunner, Faber et al. 2000).

This present findings are strongly suggestive of potent antioxidant activity of Carvedilol against ISP-induced oxidative stress in MI as previous investigations(Hori and Nishida 2009).

Histopathologic examination of cardiac tissues correlated with the observed biochemical and ECG changes as the protective effects of Carvedilol and Q10 on histopathological changes of myocardium were further supported by light microscopic observations. Subsequent to isoprenaline administration, significant myonecrosis, 
edema, and infiltration of inflammatory cells were observed in light microscopic examination of the myocardium. These histopathological perturbation in isoprenalineintoxicated rats are attributed to a decline in oxygen supply with paramount rise in wallstress(Ojha, Bhatia et al. 2011)

However, Carvedilol and Q10 treatment to ISP-intoxicated rats has shown resistance towards necrosis, edema, and inflammation and protected cardiomyocytes from the deleterious effects of isoprenaline. Such effects can be explained by previously reported anti-oxidant and anti-inflammatory potentials of Carvedilol and Q10 (Alcaraz, Fernandez et al. 2003). Rats which received Carvedilol and Q10 treatment exhibited a normal myocardial histology, which is suggestive of the fact that Carvedilol and Q10 $(5 \mathrm{mg} \& 10 \mathrm{mg} / \mathrm{kg} /$ day $)$ do not render any significant adverse effects on myocardium and is safe for myocardial cells.

\section{Conclusion}

The present study demonstrated that subcutaneous injections of isoprenaline produced myocardial infarction in rats as evident by the release of myocyte injury markers in serum. Myocardial lesions were associated with decreased antioxidant defense status in the heart electrocardiographic, histopathological changes and release of CK-MB. In addition, the present study provided experimental evidence that Carvedilol and Q10 maintained the antioxidant activity and improved cardiac performance following high-dose isoprenaline administration. This finding might be a scientific support to understand the beneficial effects of Carvedilol and Q10 on improvement of myocardial injury, in which oxidative stress has long been known to contribute to the pathogenesis.

\section{References}

Alcaraz, M., P. Fernandez, et al. (2003): "Anti-inflammatory actions of the heme oxygenase-1 pathway." Current pharmaceutical design 9(30): 2541-2551.

Ashoush, I., O. El-Batawy, et al. (2013): "Antioxidant activity and hepatoprotective effect of pomegranate peel and whey powders in rats." Annals of Agricultural Sciences 58(1): 27-32.

Brunner, M., T. S. Faber, et al. (2000): "Usefulness of carvedilol in unstable angina pectoris." The American journal of cardiology 85(10): 1173-1178.

Bullinga, J. R., R. Alharethi, et al. (2005): "Changes in heart rate variability are correlated to hemodynamic improvement with chronic CARVEDILOL therapy in heart failure." Journal of cardiac failure 11(9): 693-699.

CHANDER HASS YADAV, M. and R. KHANAM (2014): "Isoproterenol toxicity induced ECG alterations in wistar rats: role of histamine $\mathrm{H} 3$ receptor agonist imetit." IJPPS 6(5): 23-33.

Cheng, J., K. Kamiya, et al. (2001): "Carvedilol: molecular and cellular basis for its multifaceted therapeutic potential." Cardiovascular drug reviews 19(2): 152171.

Dusek, J., G. Rona, et al. (1971): "Myocardial resistance to isoprenaline in rats: variations with time." The Journal of pathology 105(4): 279-282. 
Fathiazad, F., A. Matlobi, et al. (2012): "Phytochemical screening and evaluation of cardioprotective activity of ethanolic extract of Ocimum basilicum L.(basil) against isoproterenol induced myocardial infarction in rats." DARU Journal of pharmaceutical sciences 20(1): 1 .

Field, K. J., W. J. White, et al. (1993): "Anaesthetic effects of chloral hydrate, pentobarbitone and urethane in adult male rats." Laboratory Animals 27(3): 258-269.

Gerhardt, W. and J. Waldenström (1979): "Creatine kinase B-subunit activity in serum after immunoinhibition of M-subunit activity." Clinical chemistry 25(7): 1274-1280.

Holland, R. P. and H. Brooks (1977): "TQ-ST segment mapping: critical review and analysis of current concepts." The American journal of cardiology 40(1): 110129.

Hori, M. and K. Nishida (2009): "Oxidative stress and left ventricular remodelling after myocardial infarction." Cardiovascular research 81(3): 457-464.

Jordan, J. E., Z.-Q. Zhao, et al. (1999): "The role of neutrophils in myocardial ischemia-reperfusion injury." Cardiovascular research 43(4): 860-878.

Kannan, M. M. and S. D. Quine (2013): "Ellagic acid inhibits cardiac arrhythmias, hypertrophy and hyperlipidaemia during myocardial infarction in rats." Metabolism 62(1): 52-61.

Karthikeyan, K., B. S. Bai, et al. (2007): "Efficacy of grape seed proanthocyanidins on serum and heart tissue lipids in rats subjected to isoproterenol-induced myocardial injury." Vascular pharmacology 47(5): 295-301.

Li, H., Y.-H. Xie, et al. (2012): "Cardioprotective effect of paeonol and danshensu combination on isoproterenol-induced myocardial injury in rats." PloS one 7(11): e48872.

Liu, Q., J. Zhang, et al. (2013): "Effect of carvedilol on cardiomyocyte apoptosis in a rat model of myocardial infarction: a role for toll-like receptor 4." Indian journal of pharmacology 45(5): 458.

Mladěnka, P., R. Hrdina, et al. (2009): "Cardiac biomarkers in a model of acute catecholamine cardiotoxicity." Human \& experimental toxicology 28(10): 631640.

Ojha, S., J. Bhatia, et al. (2011): "Cardioprotective effects of Commiphora mukul against isoprenaline-induced cardiotoxicity: A biochemical and histopathological evaluation." Journal of Environmental Biology 32(6): 731. 
Patel, V., A. Upaganlawar, et al. (2010): "Cardioprotective effect of melatonin against isoproterenol induced myocardial infarction in rats: a biochemical, electrocardiographic and histoarchitectural evaluation." European journal of pharmacology 644(1): 160-168.

Peacock, W. F., J. E. Hollander, et al. (2007): "Reperfusion strategies in the emergency treatment of ST-segment elevation myocardial infarction." The American journal of emergency medicine 25(3): 353-366.

Priscilla, D. H. and P. S. M. Prince (2009): "Cardioprotective effect of gallic acid on cardiac troponin-T, cardiac marker enzymes, lipid peroxidation products and antioxidants in experimentally induced myocardial infarction in Wistar rats." Chemico-biological interactions 179(2): 118-124.

Punithavathi, V. and P. Stanely Mainzen Prince (2011): "The cardioprotective effects of a combination of quercetin and $\alpha$-tocopherol on isoproterenolinduced myocardial infarcted rats." Journal of biochemical and molecular toxicology 25(1): 28-40.

Rajadurai, M. and P. S. M. Prince (2007): "Preventive effect of naringin on cardiac markers, electrocardiographic patterns and lysosomal hydrolases in normal and isoproterenol-induced myocardial infarction in Wistar rats." Toxicology 230(2): 178-188.

Upaganlawar, A., V. Patel, et al. (2012): "Tomato lycopene attenuates myocardial infarction induced by isoproterenol: Electrocardiographic, biochemical and anti-apoptotic study." Asian Pacific journal of tropical biomedicine 2(5): 345351.

Yousefi, K., H. Soraya, et al. (2013): "Cardioprotective effect of methanolic extract of Marrubium vulgare L. on isoproterenol-induced acute myocardial infarction in rats." 
تأثير الكارفيديلول والكيو 10 على سمية القلب المحدثة بواسطة الايزوبرانالين:تقييم رسم القلب

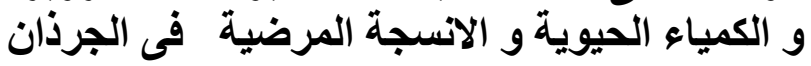

\section{للسادة الاكاترة}

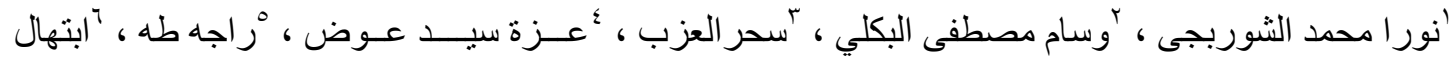

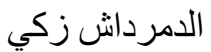

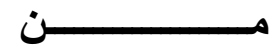

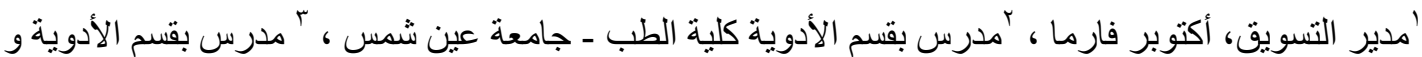

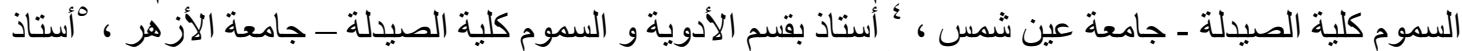

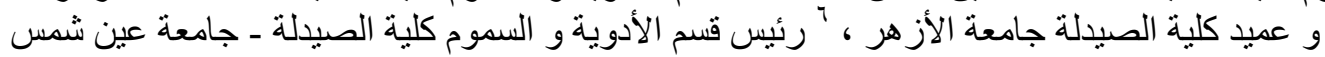

تقييم التأثير العلاجى من الجمع بين مادة الكيوتن و الكارفيديلول على التغييرات الحادثة فى رسم القلب الحي

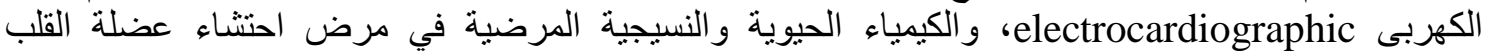

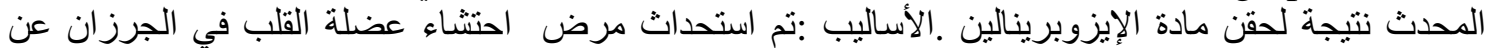

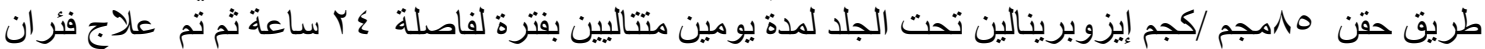

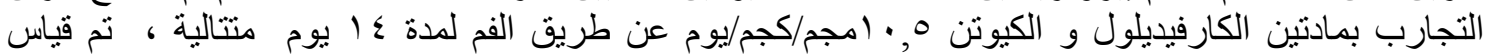

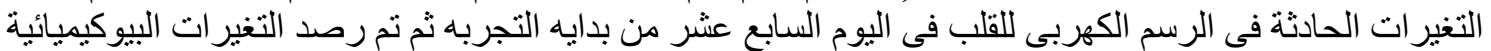

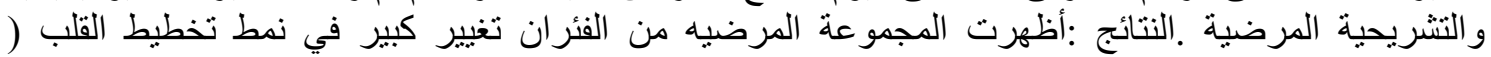
(ST,Qtc \& HR

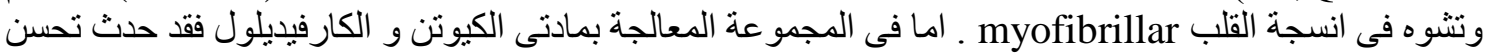

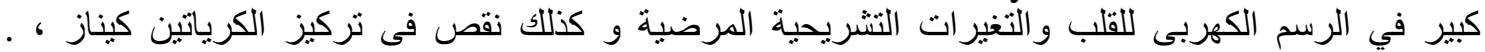
الاستتاجات: ادى تناول مادتى الكيوتن و الكارفيديلول الى التحسن فى مرض التى احتثاء عضلة القلب في الفئران الناجم عن حقن مادة الأيزوبرينالين. 